\title{
Congenital Hypothyroidism due to a Low Level of Maternal Thyrotropin Receptor- Blocking Antibodies
}

\author{
Solène Castellnou ${ }^{a}$ Patricia Bretones ${ }^{b} \quad$ Juliette Abeillon ${ }^{a} \quad$ Myriam Moret $^{a}$ \\ Pauline Perrin $^{c}$ Karim Chikh ${ }^{d}$ Véronique Raverot $^{c}$ \\ ${ }^{a}$ Hospices Civils de Lyon, Groupement Hospitalier Est, Fédération d'Endocrinologie, Bron, France; \\ bService d'Endocrinologie Pédiatrique, Hospices Civils de Lyon, Groupement Hospitalier Est, Bron, France; \\ ${ }^{c}$ Centre de Biologie et de Pathologie Est, Hospices Civils de Lyon, Groupement Hospitalier Est, LBMMS, \\ Bron, France; ${ }^{d}$ Centre de Biologie et de Pathologie Sud, Hospices Civils de Lyon, Groupement Hospitalier Sud, \\ LBMMS, Saint Genis Laval, France
}

\section{Established Facts}

- Maternal TSH receptor-blocking antibodies (TBAbs) are a known cause of transient congenital hypothyroidism.

\section{Novel Insights}

- Congenital hypothyroidism due to TBAbs can occur in case of a normal concentration of neonatal TSH receptor antibodies (TRAbs).

- In the event of a congenital hypothyroidism with gland in situ, TBAbs must be suspected when discovering a maternal hypothyroidism, even if maternal TRAbs are just above the upper limit of the reference range.

\section{Keywords}

Congenital hypothyroidism - Thyrotropin receptor-blocking antibodies $\cdot$ TRAb $\cdot$ TBAb $\cdot$ TSHR Ab

\section{Abstract \\ Introduction: Maternal TSH receptor antibodies (TRAbs) can cross the placenta and affect fetal and neonatal thyroid func- tion. Maternal TSH receptor-blocking antibodies (TBAbs) are a rare cause of congenital hypothyroidism. Case Report: Fol-}

lowing the discovery of a highly elevated TSH on her neonatal screening test, a 10-day-old girl with no familial history of thyroid disorder was referred to the pediatric endocrinology unit. Hypothyroidism was confirmed with a highly elevated TSH (817 mIU/L, reference range $0.4-3.1)$ and very low levels of FT4 (1.8 pmol/L, reference range 12-22). Anti-TPO antibodies were at $81 \mathrm{IU} / \mathrm{mL}$ (reference range $<34$ ), TRAbs at 1.7 IU/L (reference range $<1.75$ ), and thyroglobulin at $9.4 \mu \mathrm{g} / \mathrm{L}$ (reference range 3.5-77). The thyroid appeared normal on ultrasonography, and no radioiodine uptake was seen on
Véronique Raverot

Centre de Biologie et de Pathologie Est 
the scintigraphy after the perchlorate discharge test. Concomitantly, a severe maternal hypothyroidism was discovered (TSH $224 \mathrm{mIU} / \mathrm{L})$. The maternal ultrasound appeared normal, anti-TPO antibodies were moderately elevated, and TRAbs were at $3.2 \mathrm{IU} / \mathrm{L}$. TBAbs activity was measured in the mother and her daughter, and a very high and similar blocking activity was observed in both patients (TBAbs $89 \%$, reference range $<10 \%$ ). L-thyroxine treatment was introduced in the newborn and was successfully discontinued at 6.5 months of age, as the TBAbs activity decreased. Conclusion: We report herein a case of transient congenital hypothyroidism with a normal neonatal TRAbs level. In case of maternal TBAbs, similar activity of maternal TBAbs must be expected in the neonate, independently of the neonatal level of TRAbs.

(C) 2020 European Thyroid Association Published by S. Karger AG, Basel

\section{Introduction}

The most common causes of thyroid dysfunction are autoimmune diseases, some of which can be caused by antibodies such as TSH receptor antibodies (TRAbs). Two types of TRAbs can be distinguished: TSH receptorstimulating antibodies (TSAbs), which stimulate TSH receptor and lead to hyperthyroidism, and less frequently TSH receptor-blocking antibodies (TBAbs), which are competitive inhibitors of TSH binding but do not activate the receptor. The latter can induce hypothyroidism $[1,2]$. Maternal TRAbs may cross the placenta at around 16 weeks of gestation and, in addition to their impact on maternal thyroid, they can affect fetal and neonatal thyroid function. This effect can last 3 to 6 months after birth as maternal antibodies progressively disappear [3]. New- born screening for hypothyroidism is recommended in numerous countries because of the severe neurologic prognosis of congenital hypothyroidism [4], which occurs in approximately $1 / 2,000-1 / 4,000$ newborns [5]. Few cases of congenital hypothyroidism linked to maternal TBAbs have been reported [6-13], and TBAbs were found in approximately $1 \%$ of the congenital hypothyroidism cases $[10,14,15]$.

Herein we report a case of transient congenital hypothyroidism due to placental barrier crossing of maternal TBAbs, leading to the diagnosis of severe maternal hypothyroidism.

\section{Case Report}

A 10-day-old girl was referred to the pediatric endocrinology department following the discovery of highly elevated TSH (253 $\mathrm{mIU} / \mathrm{L}$, threshold value 17$)$ with low total T4 (10.8 nmol/L, threshold value 80 ) on her neonatal screening test. She was born at 42 weeks of amenorrhea, by vaginal birth after labor induction, with a birth weight of $3,450 \mathrm{~g}$. She was transferred to intensive neonatal care rapidly after her birth because of 2 desaturation episodes with cyanosis due to transient respiratory distress. Other than phototherapy sessions due to physiological icterus with a maximal total bilirubin of $292 \mu \mathrm{mol} / \mathrm{L}$ and dislocation of the left hip associated with a subluxation of the right hip managed by orthopedic treatment, she was in good health and left the hospital after 7 days. Her parents had no known thyroid disorder and she had no siblings. On the day of hospital admission, day 10 after birth, she presented with an icterus, little spontaneous motor activity, and a hoarse cry was noticed. Her weight was $3,340 \mathrm{~g}$. A thyroid test confirmed severe hypothyroidism with TSH at $817 \mathrm{mIU} / \mathrm{L}$ (reference range 0.43.1), FT4 at $1.8 \mathrm{pmol} / \mathrm{L}$ (reference range $12-22$ ), and FT3 $<2.3$ $\mathrm{pmol} / \mathrm{L}$ (reference range 2.9-4.9). Free bilirubinemia was increased at $365 \mu \mathrm{mol} / \mathrm{L}$. Anti-TPO antibodies were slightly positive at $81 \mathrm{IU} / \mathrm{mL}$ (reference range $<34$ ) and TRAbs at $1.7 \mathrm{IU} / \mathrm{L}$ were at the upper limit of the reference range $(<1.75 \mathrm{IU} / \mathrm{L})$. Anti-thyro-

Table 1. TRAbs levels assessed by two different techniques

\begin{tabular}{|c|c|c|}
\hline \multirow[t]{2}{*}{ Controlled sample } & \multicolumn{2}{|l|}{ TRAbs level (IU/L) } \\
\hline & $\begin{array}{l}\text { automated immunoassay } \\
\text { (E411, Roche Diagnostics, } \\
\text { Mannheim, Germany) } \\
\text { reference range }<1.75 \mathrm{IU} / \mathrm{L}\end{array}$ & $\begin{array}{l}\text { second-generation immunoassay } \\
\text { (Thermo Fisher Brahms TRAb human RIA) } \\
\text { reference range }<1.5 \mathrm{IU} / \mathrm{L}\end{array}$ \\
\hline Mother & 3.2 & 3.86 \\
\hline Neonate (10 days) & 1.7 & $*$ \\
\hline Neonate (5 weeks) & 0.4 & $<1$ \\
\hline Neonate (7 weeks) & $<0.3$ & $<1$ \\
\hline Neonate (18 weeks) & $<0.8^{* *}$ & $<1$ \\
\hline
\end{tabular}

* Second-generation immunoassay result could not be obtained for this sample due to an insufficient serum volume. ${ }^{* *}$ New reagent formulation (modification of the limit of quantification). 
Fig. 1. Neonate biological response under L-thyroxine treatment. Daily L-thyroxine treatment is represented below the graph. TRAbs, TSH receptor antibodies; TBAbs, TSH receptor-blocking antibodies; TSAbs, TSH receptor-stimulating antibodies.

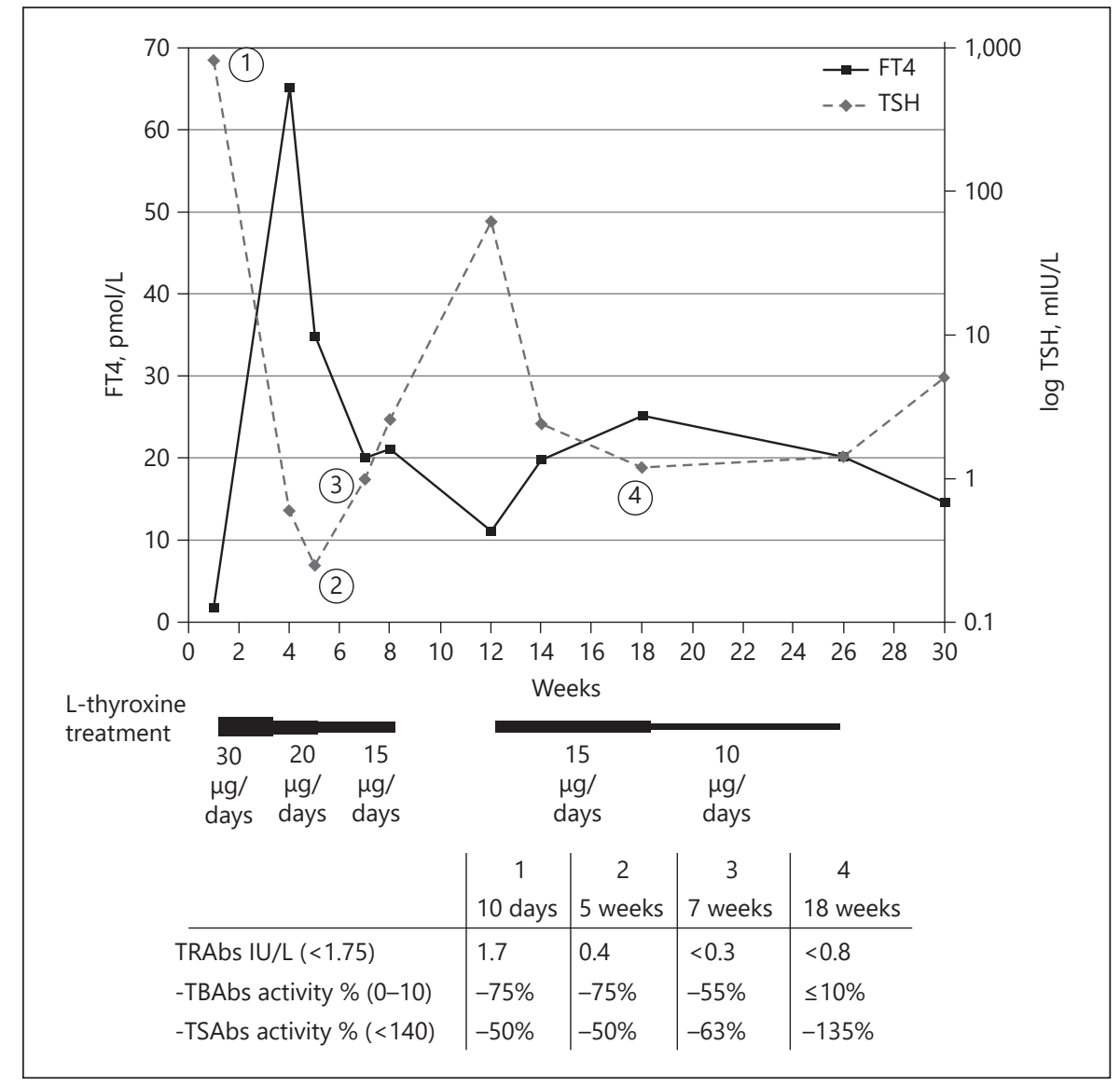

globulin antibodies were less than $25 \mathrm{IU} / \mathrm{mL}$ (reference range $<115$ ) and thyroglobulin level was $9.4 \mu \mathrm{g} / \mathrm{L}$ (reference range 3.577). The thyroid gland was eutopic with a normal size on cervical ultrasonography. However, no radioiodine uptake was seen on the thyroid scintigraphy after the perchlorate discharge test (no image was taken before the perchlorate discharge test). Ossification points of the knee were missing on radiographies. A treatment with L-thyroxine was prescribed at a dose of $30 \mu \mathrm{g} / \mathrm{day}$ and a clinical response was rapidly observed with an improvement of icterus, weight increase, and a more alert child only 3 days later.

A maternal thyroid checkup was carried out in this context and led to the discovery of severe maternal hypothyroidism with TSH at $224 \mathrm{mIU} / \mathrm{L}$ (reference range $0.4-3.1$ ), FT3 $<2.3 \mathrm{pmol} / \mathrm{L}$ (reference range 2.9-4.9), and FT4 at $2 \mathrm{pmol} / \mathrm{L}$ (reference range 12-22). Clinically, the mother reported asthenia and a weight gain of $8 \mathrm{~kg}$ the year prior to her pregnancy. Cervical ultrasound showed no anomaly. Anti-TPO antibodies were at $57 \mathrm{IU} / \mathrm{mL}$ (reference range $<34$ ), anti-thyroglobulin antibodies at $55 \mathrm{IU} / \mathrm{ml}$ (reference range $<115$ ), and thyroglobulin at $2.7 \mu \mathrm{g} / \mathrm{L}$ (reference range 3.5-77). TRAbs were moderately elevated at $3.2 \mathrm{IU} / \mathrm{L}$ (reference range $<1.75$ ), and biological activity of TRAbs was assessed by bioassay. Severely high activity of TBAbs was observed (89\%, reference range $0-10 \%$ ), and no TSAbs were detected (reference range $<140 \%)$. TRAbs activity was assessed on the neonate's sample and a similar blocking activity was observed in the mother and newborn. Because of the discrepancy between the TRAbs level mea- sured by automated immunoassay used (E411; Roche Diagnostics, Mannheim, Germany) and TRAbs activity, the results of the TRAbs level were controlled using a second-generation immunoassay (Thermo Fisher Brahms TRAb human RIA; reference range: $<1.5$ IU/L) (Table 1). As the TRAbs fell below the detection limit, with a decrease in TBAbs activity, the discontinuation of the Lthyroxine treatment was attempted at 2 months of age, resulting in an increase in TSH to $62 \mathrm{mIU} / \mathrm{L}$. Treatment was resumed and was finally successfully discontinued at 6.5 months of age (Fig. 1). After 1 month off treatment, the girl's thyroid function, weight, height, and psychomotor evolution were satisfactory. The mother was treated with L-thyroxine following her hypothyroidism diagnosis. The treatment was progressively increased until TSH normalization.

\section{Discussion}

In this case, the discovery of congenital hypothyroidism in a neonate led to the diagnosis of maternal hypothyroidism. No fetal goiter was observed during pregnancy even though it has been described in a previous case report [16]. The signs and severity of hypothyroidism may vary among newborns [13]. Symptoms of hypo- 
thyroidism such as hyperbilirubinemia, lethargy, or hoarse cry may not be immediately identified, hence the importance of neonatal screening [5]. In this case of deep hypothyroidism in both child and mother, 2 major etiologies were evoked. Firstly, the mother's hypothyroidism could have led to hypothyroidism in the newborn because of the lack of thyroxin and iodine available for fetal hormonosynthesis. However, an important radioiodine uptake would have been observed on the thyroid scintigraphy [3-5]. Secondly, the mother's hypothyroidism could have been caused by TBAbs, a hypothesis which is consistent with the absence of radioiodine uptake associated with a normal thyroid gland on ultrasound $[4,5]$ and a normal rate of thyroglobulin, although this thyroglobulin level may be considered low for a newborn with such a high TSH $[4,5,17-19]$. This second hypothesis is supported by the transitory nature of neonatal hypothyroidism in parallel with the decrease in TRAbs. Because of the hypothesis of a transient neonatal hypothyroidism due to maternal antibodies, the starting L-thyroxine dose of $9 \mu \mathrm{g} / \mathrm{kg} /$ day was lower than what is usually used in deep hypothyroidism. This case highlights the importance of assessing mothers' thyroid function in the event of congenital hypothyroidism discovery in a newborn child. Maternal TBAbs were found in the neonate due to their transplacental crossing. This is also the case for anti-TPO antibodies. However, those do not significantly affect the fetal or neonatal thyroid function [20].

The discrepancy between low level of TRAbs and high TBAbs activity in our case could be explained by (i) blocking antibodies with a very high affinity for TSH receptors or (ii) antibodies not fully detected by the automated immunoassay used. However, TRAbs measurements using a second-generation immunoassay confirmed the initial results. Cutoffs are always associated with measurement uncertainty that must be kept in mind when interpreting results. Depending on the context, even an almost normal value must be taken into account, and dialogue between clinicians and biologists can be useful in cases presenting diagnostic difficulties.

Congenital hypothyroidisms due to TBAbs are probably underestimated as TBAbs are rarely checked for in pregnant women with hypothyroidism. However, it has previously been reported that TBAbs are twice more frequent in patients with Hashimoto's thyroiditis than in patients with Grave's disease, and that TBAbs are only found in patients with autoimmune thyroid diseases [21]. The severe maternal hypothyroidism reported herein, with a very low transplacental passage of T4, has probably increased the importance of neonatal hypothyroidism. Although it is not actually recommended to screen all pregnant women or women of childbearing age for abnormal TSH $[20,22,23]$, it is important to be alert to clinical signs suggestive of hypothyroidism during pregnancy.

It has previously been reported that no congenital hyperthyroidism was found when maternal TRAbs were under $5 \mathrm{IU} / \mathrm{L}$ in the second trimester of pregnancy [24]. This may not be true for hypothyroidism due to TBAbs, as in this case, the mother's TRAbs were only at $3.2 \mathrm{IU} / \mathrm{L}$. Limitations of our findings are that maternal assays were only performed postpartum, even though pregnancy is associated with a state of immune tolerance and TRAbs decrease is usually observed. Further studies are needed to assess this issue.

\section{Acknowledgement}

We thank Agathe Antunes and Véréna Landel for their help in manuscript preparation.

\section{Statement of Ethics}

The mother gave her written informed consent to publish this case.

\section{Conflict of Interest Statement}

The authors have no conflicts of interest to declare.

\section{Funding Sources}

This research did not receive any specific grant from any funding agency in the public, commercial, or not-for-profit sector.

\section{Author Contributions}

Conceptualization: V.R., K.C., and P.B. Writing - original draft preparation: S.C., P.P., K.C., and V.R. Writing - review and editing: J.A., M.M., P.B. All authors have read and agreed to the published version of the manuscript. 


\section{References}

1 Michalek K, Morshed SA, Latif R, Davies TF. TSH receptor autoantibodies. Autoimmun Rev. 2009 Dec;9(2):113-6.

2 Diana T, Olivo PD, Kahaly GJ. Thyrotropin Receptor Blocking Antibodies. Horm Metab Res. 2018 Dec;50(12):853-62.

3 Kanike N, Davis A, Shekhawat PS. Transient hypothyroidism in the newborn: to treat or not to treat. Transl Pediatr. 2017 Oct;6(4): 349-58.

4 Léger J, Olivieri A, Donaldson M, Torresani T, Krude H, van Vliet G, et al.; ESPE-PESSLEP-JSPE-APEG-APPES-ISPAE; Congenital Hypothyroidism Consensus Conference Group. European Society for Paediatric Endocrinology consensus guidelines on screening, diagnosis, and management of congenital hypothyroidism. J Clin Endocrinol Metab. 2014 Feb;99(2):363-84.

5 Rastogi MV, LaFranchi SH. Congenital hypothyroidism. Orphanet J Rare Dis. 2010 Jun; 5(1): 17 .

6 Matsuura N, Yamada Y, Nohara Y, Konishi J, Kasagi K, Endo K, et al. Familial neonatal transient hypothyroidism due to maternal TSH-binding inhibitor immunoglobulins. N Engl J Med. 1980 Sep;303(13):738-41.

7 Zakarija M, McKenzie JM, Eidson MS. Transient neonatal hypothyroidism: characterization of maternal antibodies to the thyrotropin receptor. J Clin Endocrinol Metab. 1990 May; 70(5):1239-46.

8 McKenzie JM, Zakarija M. Fetal and neonatal hyperthyroidism and hypothyroidism due to maternal TSH receptor antibodies. Thyroid. 1992;2(2):155-9.

9 Ilicki A, Larsson A, Karlsson FA. Circulating thyroid antibodies in congenital hypothyroidism. Acta Paediatr Scand. 1991 Aug-Sep; 80(8-9):805-11.
10 Evans C, Gregory JW, Barton J, Bidder C, Gibbs J, Pryce R, et al. Transient congenital hypothyroidism due to thyroid-stimulating hormone receptor blocking antibodies: a case series. Ann Clin Biochem. 2011 Jul;48(Pt 4): 386-90.

11 Evans C, Jordan NJ, Owens G, Bradley D, Ludgate M, John R. Potent thyrotrophin receptor-blocking antibodies: a cause of transient congenital hypothyroidism and delayed thyroid development. Eur J Endocrinol. 2004 Mar;150(3):265-8.

12 Takasu N, Mori T, Koizumi Y, Takeuchi S, Yamada T. Transient neonatal hypothyroidism due to maternal immunoglobulins that inhibit thyrotropin-binding and post-receptor processes. J Clin Endocrinol Metab. 1984 Jul;59(1):142-6.

13 Brown RS, Alter CA, Sadeghi-Nejad A. Severe unsuspected maternal hypothyroidism discovered after the diagnosis of thyrotropin receptor-blocking antibody-induced congenital hypothyroidism in the neonate: failure to recognize and implications to the fetus. Horm Res Paediatr. 2015;83(2):132-5.

14 Brown RS, Bellisario RL, Botero D, Fournier $\mathrm{L}$, Abrams CA, Cowger ML, et al. Incidence of transient congenital hypothyroidism due to maternal thyrotropin receptor-blocking antibodies in over one million babies. J Clin Endocrinol Metab. 1996 Mar;81(3):1147-51.

15 Orgiazzi J. Anti-TSH receptor antibodies in clinical practice [vii.]. Endocrinol Metab Clin North Am. 2000 Jun;29(2):339-55.

16 Ohira S, Miyake M, Kobara H, Kikuchi N, Osada R, Ashida T, et al. Fetal goitrous hypothyroidism due to maternal thyroid stimulation-blocking antibody: a case report. Fetal Diagn Ther. 2010;28(4):220-4.

17 Ilicki A, Ericsson UB, Larsson A, Mortensson $\mathrm{W}$, Thorell J. The value of neonatal serum thyroglobulin determinations in the follow-up of patients with congenital hypothyroidism. Acta Paediatr Scand. 1990 Aug-Sep;79(8-9): $769-75$.
18 Pacini F, Lari R, La Ricca P, Grasso L, Di Bartolo F, Fenzi GF, et al. Serum thyroglobulin determinations in the differential diagnosis of congenital hypothyroidism. J Endocrinol Invest. $1984 \mathrm{Feb} ; 7(1): 29-33$.

19 Czernichow P, Schlumberger M, Pomarede R, Fragu P. Plasma thyroglobulin measurements help determine the type of thyroid defect in congenital hypothyroidism. J Clin Endocrinol Metab. 1983 Feb;56(2):242-5.

20 Alexander EK, Pearce EN, Brent GA, Brown RS, Chen H, Dosiou C, et al. 2017 Guidelines of the American Thyroid Association for the Diagnosis and Management of Thyroid Disease During Pregnancy and the Postpartum. Thyroid. 2017 Mar;27(3):315-89.

21 Diana T, Krause J, Olivo PD, König J, Kanitz M, Decallonne B, et al. Prevalence and clinical relevance of thyroid stimulating hormone receptor-blocking antibodies in autoimmune thyroid disease. Clin Exp Immunol. 2017 Sep; 189(3):304-9.

22 De Groot L, Abalovich M, Alexander EK, Amino N, Barbour L, Cobin RH, et al. Management of thyroid dysfunction during pregnancy and postpartum: an Endocrine Society clinical practice guideline. J Clin Endocrinol Metab. 2012 Aug;97(8):2543-65.

23 Lazarus J, Brown RS, Daumerie C, Hubalewska-Dydejczyk A, Negro R, Vaidya B. 2014 European thyroid association guidelines for the management of subclinical hypothyroidism in pregnancy and in children. Eur Thyroid J. 2014 Jun;3(2):76-94.

24 Abeillon-du Payrat J, Chikh K, Bossard N, Bretones P, Gaucherand P, Claris O, et al. Predictive value of maternal second-generation thyroid-binding inhibitory immunoglobulin assay for neonatal autoimmune hyperthyroidism. Eur J Endocrinol. 2014 Oct;171(4): $451-60$. 